\title{
Reflets
}

Revue ontaroise d'intervention sociale et communautaire

\section{Mauvais traitement des personnes âgées : un manuel pratique}

\section{Rita Mascherin}

Volume 2, numéro 2, automne 1996

Vieillir à l'aube de l'an 2000

URI : https://id.erudit.org/iderudit/026142ar

DOI : https://doi.org/10.7202/026142ar

Aller au sommaire du numéro

Éditeur(s)

Reflets : Revue ontaroise d'intervention sociale et communautaire

ISSN

1203-4576 (imprimé)

1712-8498 (numérique)

Découvrir la revue

Citer ce compte rendu

Mascherin, R. (1996). Compte rendu de [Mauvais traitement des personnes âgées : un manuel pratique]. Reflets, 2(2), 173-175.

https://doi.org/10.7202/026142ar

Tous droits réservés (C) Reflets : Revue ontaroise d'intervention sociale et communautaire, 1996
Ce document est protégé par la loi sur le droit d'auteur. L'utilisation des services d'Érudit (y compris la reproduction) est assujettie à sa politique d'utilisation que vous pouvez consulter en ligne.

https://apropos.erudit.org/fr/usagers/politique-dutilisation/ 


\section{Mauvais traitement des personnes âgées: un manuel pratique}

\section{Rita Mascherin, adjointe de direction}

Association des travailleuses et travailleurs sociaux de l'Ontario

Le mauvais traitement des personnes âgées est un phénomène complexe. Sa fréquence, son ampleur et son dépistage sont influencés par différents facteurs. Entre autres, il faut dire que l'attitude négative de la société à l'égard du vieillissement fait que les personnes âgées sont particulièrement sujettes aux mauvais traitements.

Les différents intervenants et intervenantes qui offrent des services aux personnes âgées et maltraitées ont très peu de ressources. S'occuper des personnes âgées qui, pour toutes sortes de raisons comme la dépendance financière, physique ou affective, se trouvent maltraitées, exige beaucoup de la part de tous les intervenants et intervenantes. Qu'il s'agisse du mauvais traitement à leur domicile ou en établissement, l'intervention ne sera efficace que si les personnes ont les compétences et la sensibilité voulues.

Un manuel, produit par l'Association des travailleuses et travailleurs sociaux de l'Ontario (ATTSO) en consultation avec divers fournisseurs de services et organismes s'occupant de personnes âgées, a été réalisé avec l'aide d'une subvention de Santé et bienêtre social Canada. Fruit d'une collaboration entre l'ATTSO et divers organismes et particuliers de la province, y compris les intervenants multidisciplinaires et des personnes du troisième âge, le contenu du manuel est fondé sur les connaissances actuelles et les pratiques en cours en Ontario. Pour que les services offerts 
répondent aux préoccupations et intérêts des diverses collectivités de la province, on a consulté les organismes servant les différents groupes culturels. Il s'agit d'aider les personnes qui offrent des services aux personnes âgées à reconnaitre les cas de mauvais traitements, et à gérer ces cas si nécessaire.

Le manuel, intitulé Mauvais traitement des personnes âgées: Manuel pratique à l'usage des fournisseurs de services, est un outil indispensable pour toute personne travaillant avec les personnes âgées. Cet ouvrage s'adresse aux personnes qui assurent des services à domicile, aux médecins, membres du clergé, travailleurs sociaux, personnel infirmier, personnel des hôpitaux et des organismes communautaires, étudiants, etc. Il est disponible en français et en anglais et comprend 90 pages de renseignements.

Avec ce manuel sans précédent, toutes les personnes offrant des services aux personnes âgées et maltraitées ont un guide pratique leur fournissant:

- la marche à suivre en matière d'identification et d'intervention;

- une description des victimes et des auteurs de mauvais traitements et,

- les lois et les ressources communautaires provinciales.

Le mauvais traitement des personnes âgées est un phénomène multidimensionnel englobant un vaste éventail de comportements et de situations. Il exige donc une méthode d'évaluation bien conceptualisée. Les plans d'intervention et schémas de décisions proposés dans le manuel, offrent aux praticiens la structure leur permettant de recueillir des données et de se faire une opinion claire et réfléchie de la situation. Les exemples de cas illustrent l'incidence profonde de la victimisation sur la vie des personnes âgées. Les interventions décrites aident à mieux saisir un certain nombre de réactions cliniques, et de réactions dans le cadre des programmes.

Mauvais traitement des personnes âgées: Manuel pratique à l'usage des fournisseurs de services est fortement recommandé à tous ceux et celles qui travaillent dans le but d'assurer à nos aînées et aînés 
un milieu de vie plus sûr, libre et sain. L'application des connaissances tirées de ce manuel devrait aider à soulager la souffrance d'un trop grand nombre de nos ainés canadiens.

Pour le commander, veuillez communiquer avec :

L'Atтso, 410, rue Jarvis, Toronto (Ontario) M4Y 2G6

Téléphone (416) 923-4848, télécopieur (416) 923-5279

Adresse électronique:oasw@web.net.

Le prix de l'exemplaire, y compris les frais d'affranchissement et de manutention, et la TPS, est 5,00\$. Si vous commandez 5 exemplaires ou plus, demandez un prix spécial. 